\title{
Tidligere kreftpasient i 40-årene med brystsmerter og økende dyspné
}

\author{
Dyspné hos pasienter med en kreftdiagnose er ikke uvanlig og kan \\ representere flere differensialdiagnostiske muligheter. Vi beskriver \\ et tilfelle av vedvarende og tiltakende dyspné hos en kvinne i 40-årene \\ tidligere behandlet for brystkreft med spredning til lymfeknuter.
}

Engelsk oversettelse på www.tidsskriftet.no

Se kommentar side 1881

\section{Sissel Gyrid Freim Wahl}

sissel.wahl@stolav.no

Avdeling for patologi og medisinsk genetikk

\section{Jarle Karlsen}

Kreftavdelingen

Birgit Schulz

Håkon Johansen

Klinikk for bildediagnostikk

\section{Anne Britt Abusland}

Avdeling for patologi og medisinsk genetikk

St. Olavs hospital

En kvinne i 40-årene ble innlagt i medisinsk avdeling etter ca. to måneder sykehistorie med brystsmerter med utstråling til begge aksiller. I dagene forut for innleggelsen fikk pasienten tiltakende forverring av brystsmertene, særlig ved inspirasjon og sengeleie på siden. De siste 2-3 ukene før innleggelse var hun i tillegg plaget med aktivitetsdyspné og innleggelsesdagen også taledyspné.

To år tidligere ble pasienten behandlet for lokalavansert cancer mammae $i$ venstre bryst med spredning til lymfeknuter i venstre aksille. Hun fikk neoadjuvant behandling med fire kurer cyklofosfamid og epirubicin før venstresidig ablatio og aksilletoilette, samt en kur postoperativt. Hun fikk også postoperativ strålebehandling mot thoraxvegg og regionale glandelstasjoner etter gjeldende retningslinjer. Ultralyd av lever, røntgen thorax og skjelettscintigrafi viste ingen tegn til metastatisk sykdom før oppstart av neoadjuvant behandling. Tumor var negativ for østrogen- og progesteronreseptor. Fluorescens in situ-hybridisering viste amplifikasjon av HER2-genet (HER2/kromosom 17 ratio $4 \mathrm{i}$ ca. $10 \%$ av tumorcellene). Som ledd $i$ en pågående klinisk studie ved kreftavdelingen, ble det gjennomført høyoppløsnings-CT av thorax, hjerteundersøkelse med MUGAskanning (multiple gated acquisition angio- graphy), spirometri, EKG og klinisk undersøkelse før oppstart av strålebehandling. Dette ble gjentatt etter tre, seks og 12 måneder. Ved samtlige av disse kontrollene var det normale funn ved spirometri, EKG og bildediagnostikk. Ved 12 måneders kontroll i forbindelse med studien, ca. to måneder før første innleggelse for det aktuelle, klaget pasienten over brystsmerter. Smertene ble oppfattet som muskelavhengige og man avventet videre utredning.

Dyspné hos pasienter med kreft er ikke uvanlig og kan representere flere differensialdiagnostiske muligheter, som f.eks. infeksjon, tromboembolisk sykdom, tumorembolier, solitære lungemetastaser, karsinomatøs lymfangitt, bivirkninger av kjemoterapi, hjertesvikt, hjertetamponade m.m.

EKG ved innkomst viste sinusrytme. Av blodprøver tatt ved innkomst, var troponin $T$ og CK-MB negative. D-dimer var forhøyet til $5,7 \mathrm{mg} / \mathrm{l}(0-0,5 \mathrm{mg} / \mathrm{ll}, \mathrm{CRP}$ var normal $/<10$ $\mathrm{mg} / \mathrm{ll}$. Det ble ikke tatt arteriell blodgass.

Pga. sykehistorie med dyspné og forhøyet D-dimer, mistenkte man lungeemboli. CT av lungearterier avdekket ikke lungeemboli (fig 1), men pga. mistanke om perifere lungeembolier, gikk man videre med lungescintigrafi.

Lungescintigrafi viste jevn ventilasjon bilateralt og ingen ventilasjonsdefekter, men ujevn perfusjon i begge lunger, med små, perifere perfusjonsdefekter bilateralt. Disse ble oppfattet som perifere embolier.

Man vurderte også muligheten for hjerte-/ koronaraffeksjon pga. tidligere kjemoterapi og stråling mot hjertet. Som ledd i utredningen ble pasienten også henvist til spirometri og gangtest hos lungelege.

Ekko cor viste normale funn. Spirometri og gangtest hos lungelege viste lett dyspne (dyspnéindeks 3) og fall i $\mathrm{O}_{2}$-metning under belastning, fra 98-97\% til 90-89\%, som kan ses ved blant annet pulmonal hypertensjon.

Lungeemboli ble fortsatt oppfattet som mest sannsynlig diagnose.

Pasienten ble satt på warfarin og lavmolekylært heparin (Klexane) etter vanlige retningslinjer og utskrevet etter noen få dager. Regranskning av CT av lungearterier etter utskrivning viste en metastasesuspekt lesjon i sternum og i høyre lunge samt grensestore lymfeknuter i mediastinum og fossa supraclavicularis. Pasienten ble lagt inn på nytt og man vurderte å starte kjemoterapi med docetaksel (Taxotere).

Erfaringsmessig kan warfarin være vanskelig å monitorere ved metastatisk sykdom og kan interagere med kjemoterapi. Warfarin ble derfor seponert. Man fortsatte behandling med lavmolekylært heparin i terapeutisk dose. De metastasesuspekte lesjonene ble oppfattet som for beskjedne til å kunne forklare pasientens dyspné og brystsmerter, og supplerende $\mathrm{CT}$ abdomen viste ingen øvrige metastaser. Pasienten oppga subjektiv bedring etter oppstart av antikoagulerende behandling, og diagnosen lungeemboli ble opprettholdt. Pasienten hadde sterkt ønske om å dra på ferie til utlandet, og man bestemte derfor å avvente behandling med cellegift til hun kom tilbake.

Rett før pasienten skulle på ferie lén måned etter første innleggelse for antatt lungeemboli og to uker etter forrige utskrivning), ble hun innlagt for tredje gang. Hun hadde da hatt et par dager med redusert allmenntilstand, tørrhoste, frostrier, skjelvinger, brystsmerter og økende plager med dyspné. Pasienten hadde ved innkomst temperatur $38,4^{\circ} \mathrm{C}$ og $\mathrm{pO}_{2} 8,5 \mathrm{kPa}(11,0-14,0 \mathrm{kPa})$ og $p \mathrm{CO}_{2} 3,3 \mathrm{kPa}(4,5-6,0 \mathrm{kPa})$. Under oppholdet hadde hun forbigående CRP-stigning, fra $44 \mathrm{mg} / \mathrm{l}$ ved innkomst til $123 \mathrm{mg} / \mathrm{l}$.

Luftveisinfeksjon ble oppfattet som mest sannsynlige årsak til pasientens plager.

Pga. fall i CRP (fra 123 mg/l til 103 mg/l) samt lett subjektiv bedring av symptomer ble pasienten i første omgang observert, uten behandling med antibiotika. CT av lungearterier var negativ for lungeembolier, men viste vid truncus pulmonalis $133 \mathrm{~mm}$ i motsetning til $27 \mathrm{~mm}$ ved foregående undersø- 


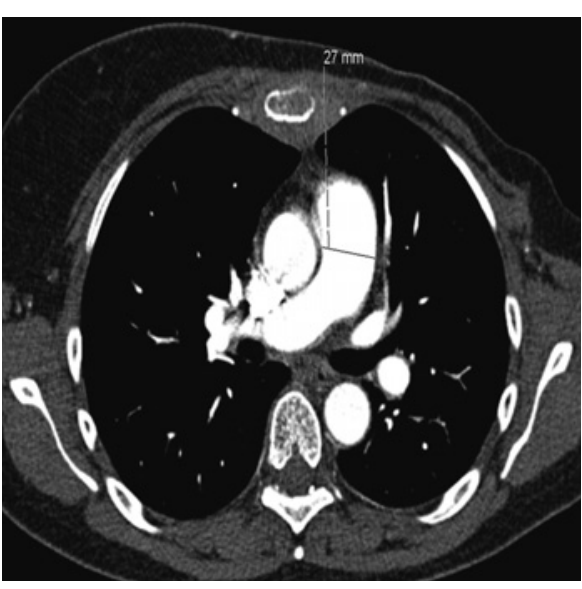

Figur 1 Volum CT thorax med intravenøs kontrast tatt ved første innleggelse. Truncus pulmonalis er normalkalibret

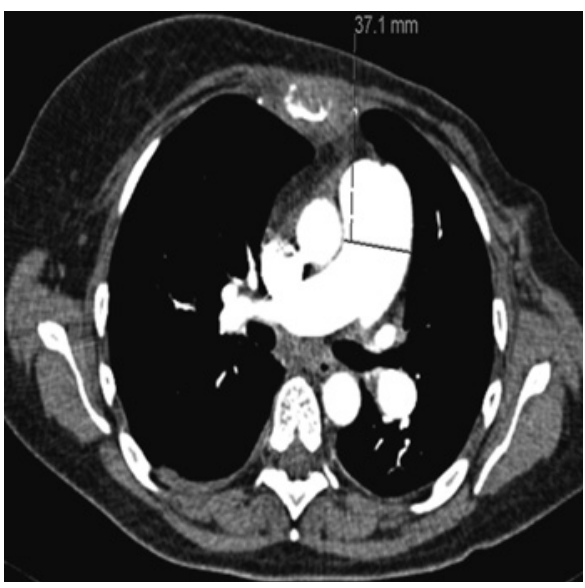

Figur 2 Volum CT thorax med intravenøs kontrast tatt under siste innleggelse viser markert truncus pulmonalis med diameter $37 \mathrm{~mm}$ som gir mistanke om pulmonal hypertensjon

kelsel som ga mistanke om pulmonal hypertensjon. For øvrig ble det påvist beskjeden vekst av metastaser.

Røntgenologisk forelå det mistanke om pulmonal hypertensjon, og man antok at dette var assosiert med lungeembolier.

Pasienten dro umiddelbart etter utskrivning på ferie. Allerede dagen etter ankomst til feriestedet ble hun innlagt på sykehus pga. tungpusthet. Etter ca. 14 dager ble hun fraktet med ambulansefly til Norge. Under flyreisen hadde pasienten fall $\mathrm{i}_{2}$-metning ved anstrengelse og behov for kontinuerlig oksygentilførsel.

Ifølge epikrisen fra utlandet ble tilstanden oppfattet som akutt astmaanfall komplisert av ledsagende infeksjon. Hun ble behandlet med bredspektret antibiotika, antiobstruktiva og prednisolon. Det ble også påvist forhøyede levermarkører, noe man trodde skyldtes mulig akutt hepatitt med bakgrunn i bruk av lavmolekylært heparin. Dette ble derfor seponert.
Supplerende undersøkelser ved innkomst sykehus viste bl.a. normal EKG, CRP $<5 \mathrm{mg} /$, leukocytter 19,3 $\cdot 10^{9} / \mathrm{l}\left(3,7-10 \cdot 10^{9} / \mathrm{l}\right), \mathrm{D}$-dimer 8,7 mg/l (0-0,5 mg/l), normale transaminaser samt normal gammaglutamyltransferase (gamma-GT), alkalisk fosfatase $(A L P)$, elektrolytter og kreatinin. Arteriell blodgass viste $\mathrm{pO}_{2} 6,0 \mathrm{kPa}$ og $\mathrm{pCO}_{2} 3,7 \mathrm{kPa}$. MRSA-prøve var negativ. Trombocyttverdi ved innkomst var $84 \cdot 10^{9} / \mathrm{l}\left(145-390 \cdot 10^{9} / \mathrm{l}\right)$. Lavmolekylært heparin ble reinnsatt etter innleggelse. Pga. ytterligere fall i trombocytter de neste dagene ble pasienten også vurdert av hematolog.

Tilstanden ble vurdert som heparinindusert trombocytopeni, og lavmolekylært heparin ble derfor erstattet med hemmer av faktor X/ $\mathrm{Xa}$, fondaparinux (Arixtra). Beinmargsutstryk og cristabiopsi viste normale funn. Man vurderte også disseminert intravaskulær koagulasjon (DIC) som mulig årsak til trombocytopeni, men blodprøver ga ingen holdepunkt for dette.

Pasienten hadde vedvarende pustebesvær, og CT thorax viste dilatert truncus pulmonalis (34 mm), forenlig med pulmonal hypertensjon. I tillegg var det tilkommet diffust utbredte, heterogene mattglassfortetninger i lungene som røntgenologisk ga mistanke om atypisk infeksjon eller akutt/ subakutt hypersensitivitetspneumonitt. Det ble derfor startet behandling med piperacillinnatrium (Tazocin) intravenøst og prednisolon. Videre ble det utført bronkoskopi med bronkoalveolær skylling pga. mistanke om infeksjon. Pga. røntgenologisk mistanke om interstitiell lungesykdom vurderte man å ta lungebiopsi, men grunnet akutt forverring og fall $\mathrm{i} \mathrm{O}_{2}$-metning, måtte prosedyren avsluttes før biopsitakning. Mikrobiologisk undersøkelse av bronkial skyllevæske viste oppvekst av Klebsiella pneumoniae, og piperacillinnatrium ble byttet ut med imipenem/ cilastatin (Tienam). Etter antibiotikaskifte fikk pasienten forbigående, kortvarig bedring, med stabil CRP rundt ca. $27-45 \mathrm{mg} / \mathrm{log}$ normal temperatur. 3-4 dager etter skifte av antibiotika fikk pasienten på ny økende tungpusthet, til tross for vedvarende behandling for lungeemboli og infeksjon samt prednisolon i etter hvert økende doser.

Pga. klinisk dominerende dyspné uten bedring ble CT- bilder av thorax vurdert på nytt av radiolog med mistanke om karsinomatøs lymfangitt. Det ble ikke funnet holdepunkt for dette eller signifikant progresjon i pasientens kreftsykdom.

CT thorax 16. innleggelsesdag viste ytterligere utvidet truncus pulmonalis, $37 \mathrm{~mm}$ (fig 2) samt tilkomne spredte, konsoliderende fortetninger $i$ venstre lunges overlapp. Sammenliknet med tidligere EKG viste nytt EKG funn som ved høyrebelastning samt $Q R$ -

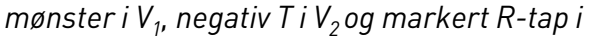

fremreveggsavledningene. Pasienten ble henvist til ekko cor, som ble planlagt neste dag. Fra samme dag ble hun tiltakende takykard og hypotensiv og ble etter hvert overflyttet til lungepostens overvåkingsavdeling for respirasjonsstøtte med BiPAP. Morgenen 18. innleggelsesdag (ca. ti uker etter aller første innleggelse for dyspnél fikk pasienten plutselig respirasjonsstans og var ikke kontaktbar. Avansert hjerte-lunge-redning ble igangsatt, men uten at man lyktes $i$ å gjenopprette egensirkulasjon. Pasienten ble erklært død ca. 30 minutter etter oppstart av resuscitering.

Obduksjon ble rekvirert, med spørsmål om årsak til pasientens vedvarende dyspné, hypoksi og påfølgende død.

Ved obduksjon var det væske i begge pleurahuler og i bukhulen. Det var to metastasesuspekte lesjoner $i$ lunge, flere $i$ lever, en $i$ sternum og i lymfeknuter $i$ lungehilus, mediastinum, paratrakealt og paraaortalt. Lungene veide $1100 \mathrm{~g}$ lgjennomsnittlig vekt for kvinner er $750 \mathrm{~g}$ ). De hadde normal størrelse og form, men var flekkvis mørkere og det var hemoragiske områder i alle lapper. Det ble ikke påvist tromber i lungearteriene. Hjertet veide $330 \mathrm{~g}$ lvanlig vekt for kvinner 200-350 g). Venstre ventrikkel var upåfallende. Høyre ventrikkel var dilatert og hadde fortykket vegg $(10 \mathrm{~mm})$, med markert trabekulering på innsiden, forenlig med cor pulmonale. Hjerteklaffer, endokard og koronararterier var upåfallende.

Mikroskopisk undersøkelse av vev fra metastasesuspekte lesjoner i lunge, lever, sternum og lymfeknuter bekreftet spredning fra adenokarsinom i mamma. I lungevevet var det flere ferske hemoragiske infarkter. I små arterier og arterioler var det multiple tumorembolier $i$ varierende stadium av organisering (fig 3, fig 4). Veggen i små arterier og arterioler var betydelig fortykket med forsnevret lumen. Forandringene var dominert av eksentrisk intimafibrose (fig 5), men det var også hypertrofi av muscularis media.

De påviste karforandringene passer med at det forelå pulmonal hypertensjon, WHO-gruppe 5 (1), med tumorembolier i små lungekar som bakenforliggende årsak. Samlet kan dette passe med pulmonal tumor trombotisk mikroangiopati (pulmonary tumor thrombotic microangiopathy, PTTM).

\section{Diskusjon}

Pulmonal tumor trombotisk mikroangiopati er vanskelig å diagnostisere og misoppfattes ofte som tromboembolisk sykdom. Andre benevnelser som brukes er karsinomatøs mikroangiopati, karsinomatøs arteriopati, karsinomatøs endarteritt og pulmonal tumoremboli. Denne tilstanden skiller seg fra vanlige tumorembolier ved at det også foreligger karforandringer som ved pulmonal hypertensjon. 
De histopatologiske forandringene avviker lite fra forandringer ved pulmonal hypertensjon som følge av tromboembolisk sykdom. Karakteristisk ses eksentrisk, men også konsentrisk, fibrose av intima (2), mild eller fraværende hypertrofi av muscularis media (i motsetning til idiopatisk pulmonal arteriell hypertensjon) samt rekanalisering av tumortromber. Tilstanden ble først beskrevet av Brill \& Robertson i 1937 som rask utvikling av høyresidig hjertesvikt grunnet tumoremboli (3). Den typiske pasienten har gjerne uttalt dyspné $(3,4)$, mens kliniske og bildediagnostiske funn kan være forholdsvis beskjedne.

Tilstanden diagnostiseres sjelden ante mortem og ses først og fremst ved obduksjon. I en studie med obduksjon av 630 pasienter med adenokarsinom, ble sykdommen påvist hos $3,3 \%$ av pasientene med solitære tumorer (5). I en annen obduksjonsstudie av pasienter med karsinom ble det funnet tumorembolier i lunge hos $40 \%$ av de obduserte (6), men i denne studien er det ikke angitt hvor mange som også hadde forandringer som ved pulmonal tumor trombotisk mikroangiopati.

Tilstanden er beskrevet ved flere typer kreft, men er hyppigst assosiert med primær tumor i lunge, mamma eller magesekk (4, 5). Den hyppige assosiasjonen med bryst- og lungekreft kan sannsynligvis tilskrives at dette er to av de vanligste kreftformene (7). De patofysiologiske mekanismene for utvikling av pulmonal hypertensjon sekundært til tumorembolier i lunge er i hovedsak ukjent, men to hypoteser er beskrevet. For det første kan dysregulering av signalveier som normalt aktiviseres ved ordinære embolier, medføre remodellering av vaskulatur og på denne måten bidra til utvikling av pulmonal hypertensjon. Den andre hypotesen beskriver økt vaskulær resistens som følge av mekanisk okklusjon av arterielle lungekar pga. tumorembolier. Når obstruksjonen har nådd

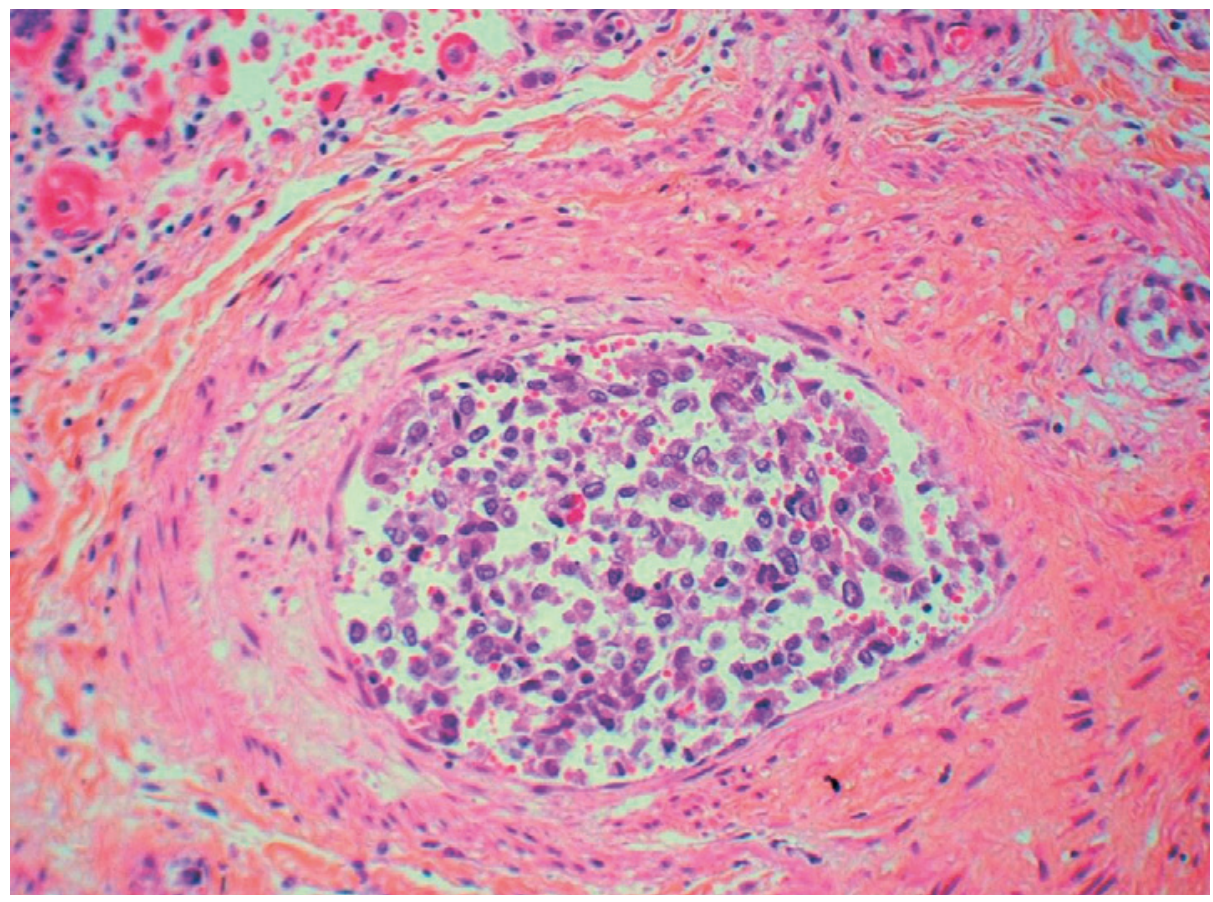

Figur 3 Liten lungearterie med tumorceller i karlumen (hematoksylin-erytrosin-safran (HES))

en bestemt terskelverdi, svekkes lungekarsengens evne til kompensasjon og symptomer oppstår (7).

Røntgen thorax kan gi informasjon om eventuelle infeksjoner, solitære lungemetastaser, interstitiell fibrose og eventuell karsinomatøs lymfangitt, men funn som kan indikere pulmonal hypertensjon og cor pulmonale ses hos færre enn $50 \%$ av pasientene med pulmonal tumor trombotisk mikroangiopati (4, 8). CT thorax bidrar også lite, men kan i noen få tilfeller vise forandringer perifert i pulmonalarteriene, da særlig subsegmentalt $\mathrm{i}$ form av dilatasjon og perlesnorsaktig utseende av perifere blodkar (beading) (9). Pulmonal angiografi er ofte normal $(7,10)$. Lungescintigrafi kan vise karakteristiske, tallrike, sym- metriske og perifere, ofte subsegmentale perfusjonsdefekter (11).

Det er beskrevet multifokalt abnormalt opptak av fluorodeoksyglukose (FDG) ved positronemisjonstomografi (PET), og dette er en undersøkelse som kan være av nytte ved utredning ved mistenkt pulmonal tumor trombotisk mikroangiopati (12). Det finnes derimot lite data om bruk av PET ved slik utredning. Lungebiopsi er av stor diagnostisk nytte, men er kontraindisert ved pulmonal hypertensjon pga. risiko for blødning $(13,14)$. Høyresidig hjertekateterisering er nødvendig for å stille diagnosen pulmonal arteriell hypertensjon, for å bedømme graden av affeksjon av høyre ventrikkels pumpefunksjon og for å teste vasoreaktiviteten

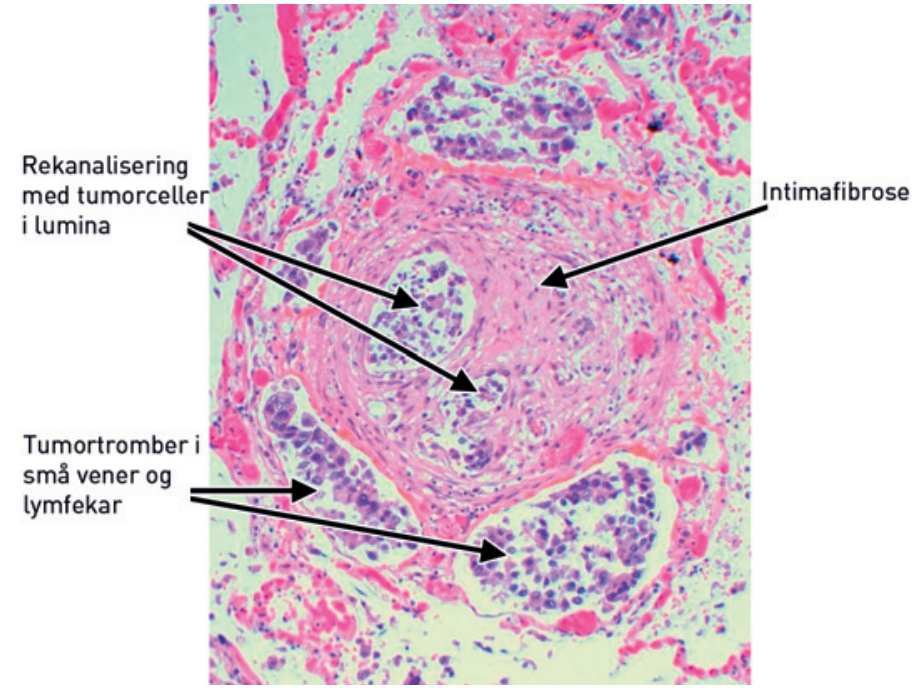

Figur 4 Arterie med intimafibrose, rekanalisering og tumortromber både i arterie og i ledsagende vener/lymfekar (HES)

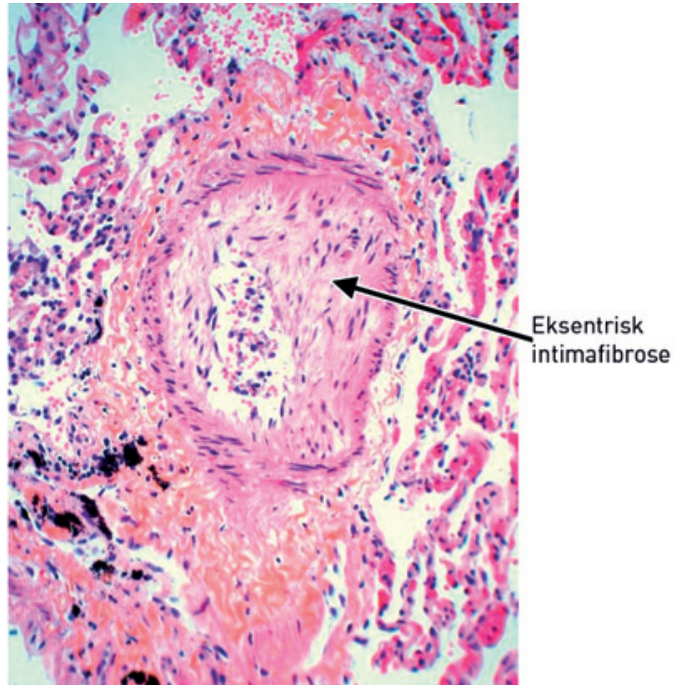

Figur 5 Liten lungearterie med eksentrisk fibrose av intima (HES) 
til pulmonal sirkulasjon på for eksempel NO. Med et pulmonalt arteriekateter er det også mulig å aspirere blod fra pulmonal mikrovaskulatur for cytologisk undersøkelse (15-17). Patolog med cytologierfaring bør konsulteres på forhånd, slik at materialet kan sikres og prepareres på best mulig måte. Av materialet kan man lage utstryk og celleblokk. Har man tilstrekkelig med tumorceller i en celleblokk, er det mulighet for supplerende spesialfarging, immunhistokjemiske og molekylærpatologiske undersøkelser. I konvensjonelle utstryk legger tumorcellene seg gjerne perifert, slik at de kan være vanskelige å oppdage. Man må være oppmerksom på at det kan forekomme forholdsvis rikelig med megakaryocytter i pulmonal vaskulatur, og at disse kan misoppfattes som tumorceller (16).

Pulmonal tumor trombotisk mikroangiopati er en aggressiv sykdom med raskt progredierende utvikling. Median overlevelse fra symptomdebut med dyspné til død anslås til 4-12 uker (2). Det finnes ingen etablert behandling for tilstanden. Vi antar at tidlig diagnose kan tilsi mer aggressiv, tumorrettet behandling og at reduksjon av tumorceller i lungesirkulasjonen muligens kan begrense risikoen for fibrointimal proliferasjon og utvikling av pulmonal hypertensjon. Det finnes derimot ingen sikre studier som kan bekrefte dette, men det er beskrevet et tilfelle av vellykket behandling hos en pasient med adenokarsinom i ventrikkel (18).

\section{Konklusjon}

Dyspné hos pasienter med kreft er ikke uvanlig og gir mange diagnostiske muligheter. Ved mistanke om lungeemboli, med eller uten tegn til pulmonal hypertensjon, må man vurdere muligheten for tumortromber ved manglende behandlingsrespons og dersom det ikke er samsvar mellom pasientens symptomer og bildediagnostiske funn. Man bør også vurdere muligheten for pulmonal tumor trombotisk mikroangiopati hos pasienter med vedvarende dyspné som ikke har kjent kreftsykdom. Selv om pasientene i utgangspunktet ofte har langtkommen kreftsykdom, bør rask utredning tilstrebes. Vi anser tverrfaglig samarbeid tidlig i forløpet som nødvendig, både for å etablere diagnose raskest mulig, men også for å unngå unødvendig utredning og behandling for andre tilstander.

Pasientens pårørende har gitt samtykke til at artikkelen blir publisert.

\section{Sissel Gyrid Freim Wahl (f. 1967)}

er spesialist i patologi og overlege ved Avdeling for patologi og medisinsk genetikk, St. Olavs hospital.

Forfatter har fylt ut ICMJE-skjemaet og oppgir ingen interessekonflikter.

\section{Jarle Karlsen (f. 1961)}

er overlege ved Kreftklinikken, St. Olavs hospital.

Forfatter har fylt ut ICMJE-skjemaet og oppgir ingen interessekonflikter.

\section{Birgit Schulz (f.1971)}

er spesialist i radiologi med to års erfaring innen onkoradiologi. For tiden er hun lege i spesialisering i nukleærmedisin.

Forfatter har fylt ut ICMJE-skjemaet og oppgir ingen interessekonflikter.

\section{Håkon Johansen (f. 1972)}

er lege ved klinikk for bildediagnostikk, St. Olavs hospital.

Forfatter har fylt ut ICMJE-skjemaet og oppgir ingen interessekonflikter.

\section{Anne Britt Abusland (f. 1946)}

er spesialist i patologi og overlege ved Avdeling for patologi og medisinsk genetikk, St. Olavs hospital.

Forfatter har fylt ut ICMJE-skjemaet og oppgir ingen interessekonflikter.

\section{Litteratur}

1. McLaughlin VV, Archer SL, Badesch DB et al. ACCF/AHA 2009 expert consensus document on pulmonary hypertension a report of the American College of Cardiology Foundation Task Force on Expert Consensus Documents and the American Heart Association developed in collaboration with the American College of Chest Physicians; Ameri can Thoracic Society, Inc.; and the Pulmonary Hypertension Association. J Am Coll Cardiol 2009 53: 1573-619.

2. von Herbay A, Illes A, Waldherr R et al. Pulmonary tumor thrombotic microangiopathy with pulmonary hypertension. Cancer 1990; 66: 587-92.

3. Brill IC, Robertson TD. Subacute cor pulmonale. Arch Intern Med 1937; 60: 1043-57.

4. Kane RD, Hawkins HK, Miller JA et al. Microscopic pulmonary tumor emboli associated with dyspnea. Cancer 1975; 36: 1473-82

5. Shields DJ, Edwards WD. Pulmonary hypertension attributable to neoplastic emboli: an autopsy study of 20 cases and review of literature. Cardiovasc Pathol 1992; 1: 279-87.

6. Soares FA, Landell GAM, de Oliveira JAM. Clinical aspects of tumour involvement of the pulmonary vessels. Acta Oncol 1992: 31: 519-23.

7. Roberts KE, Hamele-Bena D, Saqi A et al. Pulmonary tumor embolism: a review of the literature. Am J Med 2003; 115: 228-32.

8. Bassiri AG, Haghighi B, Doyle RL et al. Pulmonary tumor embolism. Am J Respir Crit Care Med 1997; 155: 2089-95

9. Shepard JA, Moore EH, Templeton PA et al. Pulmonary intravascular tumor emboli: dilated and beaded peripheral pulmonary arteries at CT. Radiology 1993; 187: 797-801.

10. Schriner RW, Ryu JH, Edwards WD. Microscopic pulmonary tumor embolism causing subacute cor pulmonale: a difficult antemortem diagnosis. Mayo Clin Proc 1991. 66: 143-8

11. Crane R, Rudd TG, Dail D. Tumor microembolism: pulmonary perfusion pattern. J Nucl Med 1984; 25 877-80.

12. Tashima Y, Abe K, Matsuo Y et al. Pulmonary tumor thrombotic microangiopathy: FDG-PET/CT findings. Clin Nucl Med 2009; 34: 175-7.

13. Bolliger CT, Mathur PN, Beamis JF et al. ERS/ATS statement on interventional pulmonology. European Respiratory Society/American Thoracic Society. Eur Respir J 2002; 19: 356-73.

14. Manhire A, Charig M, Clelland C et al. Guidelines for radiologically guided lung biopsy. Thorax 2003; 58: $920-36$

15. Masson RG, Ruggieri J. Pulmonary microvascular cytology. A new diagnostic application of the pulmonary artery catheter. Chest 1985; 88: 908-14.

16. Abati A, Landucci D, Danner RL et al. Diagnosis of pulmonary microvascular metastases by cytologic evaluation of pulmonary artery catheter-derived blood specimens. Hum Pathol 1994; 25: 257-62.

17. Babar SI, Sobonya RE, Snyder LS. Pulmonary microvascular cytology for the diagnosis of pulmonary tumor embolism. West J Med 1998. 168: 47-50.

18. Miyano S, Izumi S, Takeda Y et al. Pulmonary tumor thrombotic microangiopathy. J Clin Oncol 2007; 25: 597-9.

Mottatt 31.10. 2011, første revisjon innsendt 5.3. 2012, godkjent 10.5. 2012. Medisinsk redaktør Siri Lunde. 